\title{
Avaliação do Feno de Egeria densa na Alimentação de Carneiros ${ }^{1}$
}

\section{Ângela Maria Vieira Batista², Francisco Fernando Ramos de Carvalho², Carlo Aldrovandi Torreão Marques $^{3}$, Sílvio José Souza de Medeiros ${ }^{4}$, Omer Cavalcante de Almeida ${ }^{5}$}

\begin{abstract}
RESUMO - Este experimento foi realizado com o objetivo de avaliar o efeito da inclusão de Egeria densa na ração sobre o consumo voluntário, o ganho de peso e a conversão alimentar de ovinos Santa Inês. Dezesseis ovinos foram distribuídos ao acaso em quatro tratamentos: $\mathrm{T} 0=81 \%$ de feno de tifton $(\mathrm{FT})$ e $19 \%$ de concentrado (farelo de soja e milho); T27 = $27 \%$ de feno de Egeria (FE), 54\% de FT e 19\% de concentrado; T54-54\% de FE, $27 \%$ de FT e $19 \%$ de concentrado e T 81 $=81 \%$ de FE e $19 \%$ de concentrado. Verificou-se que o consumo voluntário foi reduzido, e o ganho de peso, quando analisado todo o período experimental, não foi afetado pela adição de feno de Egeria. Durante o período experimental, verificouse que o ganho de peso foi uniforme nos animais que receberam as dietas sem e com $27 \%$ feno de Egeria. Quando as dietas continham 54 e $81 \%$ de feno de Egeria, o ganho de peso apresentou comportamento quadrático. Apesar da alta concentração de alguns elementos minerais, a Egeria tem potencial como forrageira para ovinos, desde que seja fornecida em baixa proporção na ração ou por curto período.
\end{abstract}

Palavras-chave: consumo, degradabilidade, ganho de peso, minerais, Santa Inês, toxidez

\section{Egeria densa Hay Inclusion in Ration for Sheep}

\begin{abstract}
Sixteen Santa Inês sheep were randomly allotted to four treatments (T0 $=81 \%$ tifton hay (TH) and $19 \%$ concentrate (soybean meal and corn); T27 $=27 \%$ egeria hay $(\mathrm{EH}), 54 \% \mathrm{TH}$ and $19 \%$ concentrate; $\mathrm{T} 81=81 \% \mathrm{EH}$ and $19 \%$ concentrate) to evaluate the effect of Egeria hay inclusion in the diet on voluntary intake, weight gain and feed efficiency. Voluntary intake reduced and body weight gain was not affected by EH inclusion. During the experimental period, weight gain was similar for the animals fed diet without or with $27 \%$ EH. EH inclusion (at levels of 54 and $81 \%$ ) affected quadractricaly body weight gain. Despite of the high minerals concentration, EH could be used as forage in small quantity or for short period.
\end{abstract}

Key Words: degradability, feed intake, minerals, weight gain, Santa Inês, toxicity

\section{Introdução}

A Egeria densa é uma planta aquática, submersa, da família Hydrocharitaceae, originária da América do Sul, encontrada em rios e lagos, onde forma densas populações. Em muitos países, a Egeria é considerada uma praga aquática, em decorrência de problemas que causa nos reservatórios (Bini et al., 1999; Wilcock et al., 1999). No Brasil, a Egeria tem sido encontrada em muitos reservatórios (Maurice, 1983; Bini et al., 1999), entre eles, os lagos do complexo Paulo Afonso e Itaparica, onde cresce em profundidades de até $10 \mathrm{~m}$.
Para controlar a invasão por Egeria, tem-se aplicado métodos químico-biológicos. No entanto, os altos custos, a concentração de produtos fitotóxicos na água, a contaminação dos cursos d'água e os problemas ambientais limitam ou impedem o uso de herbicidas (Browmer et al., 1979; Sculthorpe, 1967, citado por Maurice et al., 1983).

O reservatório de Paulo Afonso está localizado no semi-árido nordestino, onde a produção de forragem é escassa na época seca. Nesse reservatório, tem-se verificado que eqüídeos, bovinos e suínos consomem Egeria espontaneamente. Portanto, se o feno de Egeria não causar efeitos adversos e apresentar bom

\footnotetext{
${ }^{1}$ Financiado pela CHESF.

2 Professores do Departamento de Zootecnia-UFRPE, Rua Dom Manoel de Medeiros S/N, Dois Irmãos, Recife, PE, CEP: 52171-900. E.mail: abatista@ufrpe.br

3 Aluno de graduação em Zootecnia, bolsista PIBIC-CNPq/UFRPE.

${ }^{4}$ Aluno de graduação em Zootecnia, bolsista CHESF.

5 Zootecnista, Departamento de Zootecnia-UFRPE.
} 
valor nutricional, poderá ser utilizado na alimentação animal, como forma de controle do crescimento da planta, além de ser uma alternativa para alimentação animal no semi-árido.

Objetivou-se, neste trabalho, determinar a composição química, as degradabilidade da matéria seca (MS) e o efeito da adição do feno de Egeria na ração sobre o consumo e o ganho de peso de ovinos.

\section{Material e Métodos}

A Egeria foi colhida no sistema hidroelétrico de Paulo Afonso, seca ao sol, durante 24 horas, e transportada para a UFRPE. Foi processada em moinho tipo Willey, com peneira de 20 mesh. Em seguida, foram determinados os teores de matéria seca (MS), matéria orgânica (MO), proteína bruta (PB), energia bruta, fibra em detergente neutro (FDN), fibra em detergente ácido (FDA), lignina, sílica e minerais (Silva, 1990).

Para determinação da degradabilidade, foram utilizados dois bovinos adultos, mestiços holandozebus, com peso vivo médio de $400 \mathrm{~kg}$, fistulados no rúmen. Os animais foram mantidos em baias individuais e receberam diariamente $30 \mathrm{~kg}$ de capimelefante picado e $2 \mathrm{~kg}$ de concentrado. A ração foi fornecida em duas porções diárias, às 8 e $16 \mathrm{~h}$. Água e sal mineral foram oferecidos à vontade.

Foram pesados $4 \mathrm{~g}$ de amostra e depositados no interior de sacos de náilon, medindo 7 x $18 \mathrm{~cm}$, com porosidade de 36 micra, previamente pesados e identificados. Os sacos foram incubados no rúmen durante $2,4,6,8,12,24,48,72$ e 96 horas e, em seguida, lavados em lavadora automática e secos em estufa com circulação forçada de ar, a $50^{\circ} \mathrm{C}$, por 72 horas.

A partir dos valores de desaparecimento da MS no rúmen, foram estimados os coeficientes da equação $\mathrm{p}=\mathrm{a}+\mathrm{b}\left(1-\mathrm{e}^{\mathrm{ct}}\right)$, proposta por Orskov e MacDonald (1979), além da degradabilidade efetiva e potencial.

O experimento foi executado no Setor de Caprinocultura do Departamento de Zootecnia da Universidade Federal Rural de Pernambuco, em Recife.

Dezesseis ovinos Santa Inês, machos, castrados, com peso vivo inicial médio de $30 \mathrm{~kg}$, foram distribuídos em quatro tratamentos, que consistiram da inclusão de feno de Egeria, nos níveis de 0,27, 54 e $81 \%$ da
MS da ração, em substituição ao feno de tifton (Tabela 2).

As dietas, compostas por feno de tifton, feno de Egeria, farelo de soja e milho moído, foram calculadas para obtenção de $70 \mathrm{~g}$ de ganho de peso diário (NRC, 1985) (Tabela 1). Os animais foram pesados e alojados em baias individuais, onde permaneceram por dez semanas para avaliação do consumo e do ganho de peso e, após duas semanas de adaptação, foram novamente pesados, quando iniciou o período experimental. Para avaliação do ganho de peso, os carneiros foram pesados em intervalos de 28 dias.

Antes da distribuição da ração, diariamente, as sobras foram coletadas, pesadas e, após homogeneização, foram reservados $20 \%$ para composição de uma amostra composta, semanal, por animal.

Amostras do ofertado e das sobras foram secas a $50^{\circ} \mathrm{C}$ por 72 horas e processadas em moinho com peneira de crivo de $1 \mathrm{~mm}$, para determinação da matéria seca (MS), matéria orgânica (MO), fibra em detergente neutro (FDN) e fibra em detergente ácido (FDA) (Silva, 1990).

Os dados foram submetidos a análise de regressão, utilizando-se o procedimento GLM do SAS (1996).

Tabela 1- Porcentagem dos ingredientes das dietas experimentais, com base na matéria seca

Table 1 - Ingredient percentage of experimental diets on dry matter basis

\begin{tabular}{lcccc}
\hline & \multicolumn{3}{c}{$\begin{array}{c}\text { Nível de inclusão de feno de Egeria } \\
\text { Level of Egeria hay inclusion }\end{array}$} \\
\cline { 2 - 5 } & 0 & 27 & 54 & 81 \\
\hline $\begin{array}{l}\text { Ingredient } \\
\begin{array}{l}\text { Ingredient } \\
\text { Feno de tifton } \\
\text { Tifton hay }\end{array}\end{array}$ & 81,0 & 54,0 & 27,0 & 0,0 \\
$\begin{array}{l}\text { Feno de Egeria } \\
\text { Egeria hay }\end{array}$ & 0,0 & 27,0 & 54,0 & 81,0 \\
$\begin{array}{l}\text { Farelo de soja } \\
\text { Soybean meal } \\
\text { Milho }\end{array}$ & 16,0 & 10,0 & 4,0 & - \\
$\begin{array}{l}\text { Corn } \\
\text { Total } \\
\text { Total }\end{array}$ & 3,0 & 8,2 & 15,0 & 19,0 \\
\hline
\end{tabular}


Tabela 2 - Composição química das rações experimentais

Table 2 - Chemical composition of the experimental diets

\begin{tabular}{lcccc}
\hline & \multicolumn{4}{c}{$\begin{array}{c}\text { Nível de inclusão de feno de Egeria } \\
\text { Level of Egeria hay inclusion }\end{array}$} \\
\cline { 2 - 5 } & 0 & 27 & 54 & 81 \\
\hline $\begin{array}{l}\text { Matéria seca (\%) } \\
\begin{array}{l}\text { Dry matter (\%) } \\
\text { Matéria orgânica (\% da MS) }\end{array}\end{array}$ & 87,55 & 88,29 & 88,97 & 89,77 \\
$\begin{array}{l}\text { Organic matter (\% of dry matter) } \\
\text { Proteína bruta (\% da MS) }\end{array}$ & 14,03 & 14,40 & 14,11 & 14,98 \\
$\begin{array}{l}\text { Crude protein (\% of dry matter) } \\
\text { FDN (\% da MS) }\end{array}$ & 71,35 & 61,13 & 51,03 & 40,71 \\
NDF (\% of dry matter) & & 88,63 & 85,78 & 82,77 \\
$\begin{array}{l}\text { FDA (\% da MS) } \\
\text { ADF (\% of dry matter) }\end{array}$ & 36,80 & 34,09 & 30,84 & 28,09 \\
\hline
\end{tabular}

\section{Resultados e Discussão}

Verificou-se baixo teor de MS na Egeria densa, o que era esperado, por tratar-se de uma planta aquática. No entanto, isto não constituiu problema, uma vez que este material foi fenado antes do fornecimento aos animais (Tabela 3 ).

O teor de PB do feno de Egeria (16,44\% na MS) é comparável ao de algumas leguminosas e pode contribuir para aumentar a proteína total da dieta, sobretudo quando se utilizam volumosos de baixo valor nutricional.

Um fato preocupante é o alto conteúdo de sílica da Egeria, pois pode afetar a digestibilidade e, conseqüentemente, o consumo. Observou-se elevada concentração de minerais, especialmente $\mathrm{Fe}, \mathrm{Mn}, \mathrm{Al}$ e Cd, o que está de acordo com resultados obtidos por Maurice et al. (1983) e Marques et al. (1999). A concentração de minerais na planta está diretamente relacionada com o nível de minerais na água e no solo. No reservatório de Paulo Afonso, a alta concentração desses minerais está ligada possivelmente à intensa atividade agrícola desenvolvida nas margens do rio São Francisco, nos projetos de irrigação. McLaughlin et al (1999) verificaram que a adubação fosfatada é a principal fonte de contaminação do $\mathrm{Cd}$ e que, em culturas desenvolvidas em regiões alagadiças e ácidas, ocorre maior solubilidade e disponibilidade desse elemento para as plantas.

Alta concentração de $\mathrm{Fe}$ e $\mathrm{Mn}$ em plantas forrageiras tropicais foi relatada por Conrad et al (1985), que concluíram que esta característica seria consequiência, além das atividades antropológicas, da acidez presente na maioria dos solos tropicais, resultando em maior disponibilidade desses elementos para as plantas.

A avaliação do fracionamento pela digestibilidade in situ revelou que a fração solúvel é alta $(\mathrm{a}=36,3 \%)$, com média degradabilidade potencial $(\mathrm{b}=53,9 \%)$ e c $=0,04$. A degradabilidade efetiva, calculada para taxa de passagem de 0,05 , foi de $90,3 \%$.

$\mathrm{O}$ feno de Egeria foi bem aceito pelos animais. Verificou-se, entretanto, que na primeira semana após sua confecção, o feno apresentava forte odor de peixe, o que causava rejeição pelos carneiros. Quando fornecido após duas ou três semanas, os animais consumiam avidamente o feno, possivelmente por haver diminuído consideravelmente o odor inicial.

Houve efeito linear decrescente do consumo de matéria seca em função da inclusão do feno de Egeria na ração (Tabela 4). A redução no consumo pode está relacionada com a alta concentração de Fe, Cd e Mn no feno de Egeria, corroborando a afirmação de Van Ravenswaay et al (2001), de que níveis altos de $\mathrm{Fe}$, combinados com longo período de fornecimento, ocasionam redução no consumo. Church (1988) e NRC (1992) relatam que $\mathrm{Cd}$ e $\mathrm{Mn}$, além do $\mathrm{Fe}$, reduzem a ingestão de matéria seca quando fornecidos em elevadas concentrações na ração.

Avaliando-se o ganho de peso médio diário em todo o período experimental (Tabela 6), não se observou efeito $(\mathrm{P}>0,05)$ da inclusão de feno de Egeria na ração. Contudo, quando se avaliou o comportamento dos animais ao longo do período experimental, constatou-se que, nos primeiros 30 dias, o ganho de peso tendeu a aumentar em função da inclusão de Egeria na ração, enquanto, nos períodos subseqüentes, o ganho médio diário foi reduzido nos 
Tabela 3 - Composição química e mineral de Egeria densa, na base da matéria seca

Table 3 - Chemical and mineral composition of Egeria densa, in dry matter basis

\begin{tabular}{|c|c|c|c|c|c|}
\hline & \multirow[t]{2}{*}{$\%$} & \multicolumn{4}{|c|}{$\begin{array}{l}\text { Minerais } \\
\text { Minerals }\end{array}$} \\
\hline & & \multicolumn{3}{|c|}{$\%$} & $\mathrm{mg} / \mathrm{kg}$ \\
\hline Matéria seca & 11,8 & $\mathrm{Ca}$ & 1,17 & $\mathrm{Cu}$ & 9,10 \\
\hline Dry matter & & & & & \\
\hline Cinzas & 20,9 & $\mathrm{P}$ & 0,21 & $\mathrm{Zn}$ & 54,40 \\
\hline Ash & & & & & \\
\hline Proteína bruta & 16,44 & $\mathrm{Mg}$ & 0,41 & B & 43,84 \\
\hline Crude protein & & & & & \\
\hline $\begin{array}{l}\text { Fibra em detergente neutro } \\
\text { Neural detergent fiber }\end{array}$ & 44,7 & $\mathrm{Fe}$ & 0,61 & $\mathrm{Ba}$ & 163,0 \\
\hline $\begin{array}{l}\text { Fibra em detergente ácido } \\
\text { Acid detergent fiber }\end{array}$ & 33,2 & $\mathrm{Al}$ & 0,74 & $\mathrm{Ti}$ & 226,0 \\
\hline Hemicelulose & 8,6 & $\mathrm{Na}$ & 0,53 & $\mathrm{~V}$ & 9,76 \\
\hline Hemicelulose & & & & & \\
\hline Celulose & 15,2 & K & 2,93 & $\mathrm{Ni}$ & 4,92 \\
\hline Celulose & & & & & \\
\hline Lignina & 11,46 & $\mathrm{~S}$ & 0,31 & $\mathrm{Sr}$ & 110,0 \\
\hline Lignin & & & & & \\
\hline Sílica & 8,70 & $\mathrm{Mn}$ & 0,70 & $\mathrm{Cd}$ & 1,18 \\
\hline Silica & & & & & \\
\hline Energia bruta (kcal/kg) & $3.850,00$ & & & $\mathrm{Co}$ & 2,85 \\
\hline Gross energy ( $\mathrm{kcal} / \mathrm{kg})$ & & & & & \\
\hline & & & & $\begin{array}{l}\mathrm{Cr} \\
\mathrm{Mo}\end{array}$ & $\begin{array}{l}<10 \\
<0,5\end{array}$ \\
\hline & & & & $\mathrm{Pb}$ & $<5,0$ \\
\hline
\end{tabular}

Tabela 4 - Consumos médios diários de matéria seca, matéria orgânica e proteína bruta por carneiros recebendo rações com diferentes percentuais de Egeria densa

Table 4 - Dry matter, organic matterand crude protein average daily intake by sheep fed diets with different Egeria hay levels

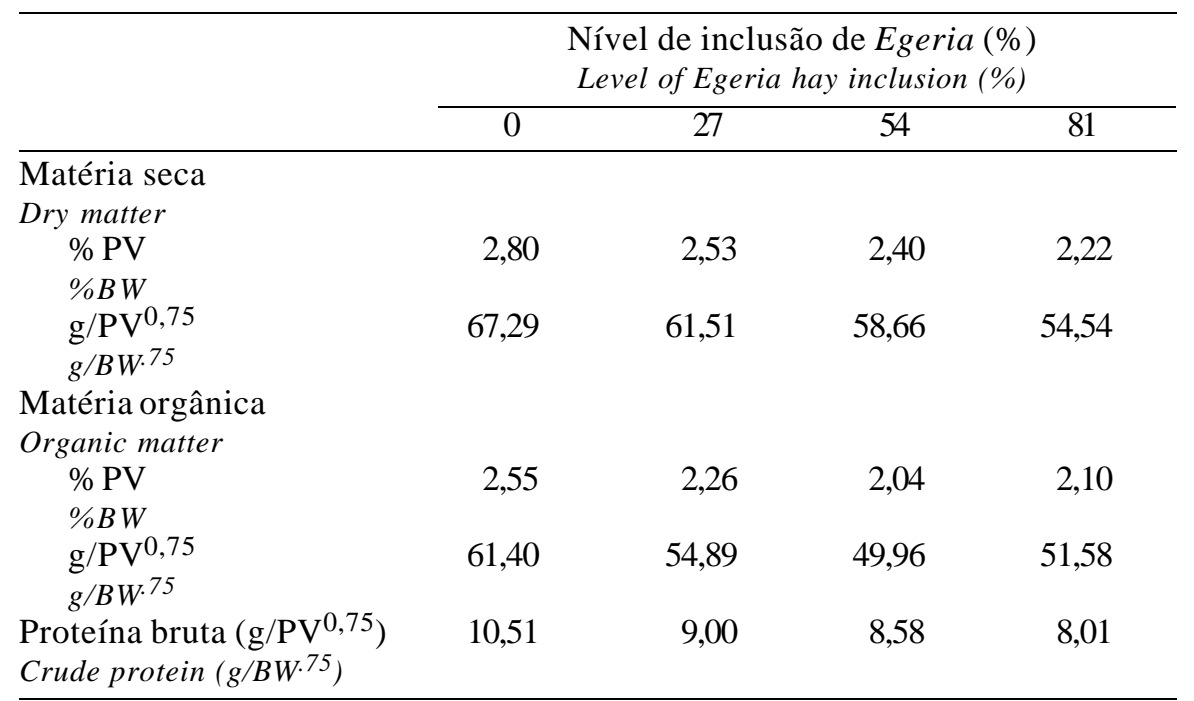


animais que receberam maiores percentuais de Egeria, resultando, inclusive, em perda de peso no último período.

Para o efeito do tempo dentro dos tratamentos, verificou-se comportamento diferente. O ganho de peso dos ovinos foi uniforme durante todo o período experimental, quando os animais receberam as dietas sem e com 27\% de Egeria (P>0,05). Entretanto, para as dietas com 54 e $81 \%$, o ganho de peso teve comportamento quadrático $(\mathrm{P}<0,05)$ (Tabela 6).

Esses resultados estão, provavelmente, relacionados com os altos níveis de minerais das rações. Verificou-se ingestão de $\mathrm{Mn}, \mathrm{Fe}, \mathrm{Al}$ e $\mathrm{Cd}$ acima dos níveis máximos recomendados pelo NRC (1992) nas rações com 54 e $81 \%$ de Egeria (Tabela 5). A inclusão de $27 \%$ de Egeria resultou em aumento na ingestão de $\mathrm{Al}$ de cerca de duas vezes, em relação ao nível de tolerância recomendado pelo NRC (1992), porém, não parece ter havido efeito tóxico, uma vez que essa ração propiciou maior ganho médio diário que a ração sem Egeria, em todos os períodos. O fato de o $\mathrm{Al}$ não se encontrar na forma de sal (forma mais disponível), mas em material orgânico, talvez possa explicar esse resultado. É também provável que o percentual de $\mathrm{P}$ na ração, acima da exigência dos animais, tenha contribuído para o não-desenvolvimento de problemas, em conseqüência da elevada ingestão de Al, uma vez que o principal efeito tóxico do $\mathrm{Al}$ é decorrente de sua ligação com o $\mathrm{P}$, formando quelatos que o tornam indisponível (Conrad et al., 1985; NRC, 1992). Valdivia et al. (1982) relataram que concentração acima de $2 \mathrm{~g}$ de $\mathrm{Al} / \mathrm{kg}$ de MS reduziu o consumo e a absorção de $\mathrm{P}$ por carneiros.

Nos tratamentos com maiores níveis de feno de Egeria (54 e 81\%), verificou-se consumo de minerais, especialmente $\mathrm{Mn}, \mathrm{Fe}, \mathrm{Al}$ e $\mathrm{Cd}$, muito acima dos níveis tóxicos preconizados pelo NRC (1992). Observou-se também que, apesar da alta ingestão de minerais pelos animais submetidos a esses tratamentos, os carneiros ganharam peso nos dois primeiros períodos experimentais. O ganho inicial foi atribuído, possivelmente, à melhor relação energia:proteína, proporcionada pela maior quantidade de milho, nas rações com maior percentual de feno de Egeria, e à baixa concentração desses elementos minerais no organismo dos animais.

O Cd é pobremente absorvido quando ingerido na forma de sal inorgânico, particularmente por ruminantes, que, geralmente, absorvem menos de $1 \%$ desse mineral (Neathery et al., 1974; Van Bruwaene et al., 1984). Lee et al. (1996) verificaram que menos de $0,25 \%$ do $\mathrm{Cd}$ ingerido diariamente foi retido nos rins e fígado de ovinos. Esses autores concluíram que o aumento na concentração de $\mathrm{Cd}$ nos rins estava diretamente relacionado com o tempo de exposição do animal ao elemento e que a maior taxa de

Tabela 5 - Consumos médios diários de minerais por carneiros recebendo rações com diferentes percentuais de Egeria densa

Table 5 - Minerals mean daily intake by sheep

\begin{tabular}{|c|c|c|c|c|}
\hline & \multicolumn{4}{|c|}{$\begin{array}{l}\text { Nível de inclusão de egéria (\%) } \\
\text { Level of Egeria hay inclusion (\%) }\end{array}$} \\
\hline & 0 & 27 & 54 & 81 \\
\hline \multicolumn{5}{|c|}{ Minerais (g/kg de MS) } \\
\hline \multicolumn{5}{|c|}{ Minerals (g/kg DM) } \\
\hline $\mathrm{Ca}$ & 3,988 & 6,454 & 8,302 & 9,378 \\
\hline $\mathrm{P}$ & 3,351 & 3,128 & 2,886 & 2,660 \\
\hline $\mathrm{Mg}$ & 2,466 & 3,017 & 2,867 & 3,633 \\
\hline $\mathrm{Fe}$ & 0,032 & 1,885 & 3,678 & 4,867 \\
\hline $\mathrm{Al}^{\mathrm{a}}$ & 0,000 & 2,260 & 4,446 & 5,895 \\
\hline $\mathrm{K}$ & 16,247 & 20,178 & 23,452 & 24,387 \\
\hline $\mathrm{Na}$ & 0,073 & 1,680 & 3,242 & 4,279 \\
\hline $\mathrm{S}$ & 1,071 & 1,729 & 2,410 & 2,865 \\
\hline \multicolumn{5}{|c|}{$\mathrm{mg} / \mathrm{kg}$ de $\mathrm{MS}$} \\
\hline \multicolumn{5}{|c|}{$m g / k g D M$} \\
\hline Mn & 7,15 & 524,22 & 1024,44 & 1356,05 \\
\hline $\mathrm{Cd}^{\mathrm{b}}$ & 0,00 & 0,36 & 0,71 & 0,94 \\
\hline Ca:P & 1,19 & 2,06 & 2,88 & 3,52 \\
\hline
\end{tabular}

a Não foi considerado o fornecido pelo feno de Tifton.

b Considerado apenas o fornecido pelo feno de Egeria densa.

R. Bras. Zootec., v.33, n.5, p.1309-1315, 2004 
Tabela 6 - Ganho de peso de carneiros consumindo rações com diferentes percentuais de Egeria densa

Table 6 - Weight gain of sheep fed diets with different Egeria hay levels

\begin{tabular}{|c|c|c|c|c|c|c|}
\hline & \multicolumn{4}{|c|}{$\begin{array}{l}\text { Nível de inclusão de Egeria } \\
\text { Level of Egeria hay inclusion (\%) }\end{array}$} & \multicolumn{2}{|c|}{$\operatorname{Pr}>\mathrm{F}$} \\
\hline & 0 & 27 & 54 & 81 & $\mathrm{~L}$ & $\mathrm{Q}$ \\
\hline \multicolumn{7}{|l|}{$\begin{array}{l}\text { Ganho médio diário }(\mathrm{g}) \\
\text { Mean daily gain }(\mathrm{g})\end{array}$} \\
\hline $\begin{array}{l}\text { Total } \\
\text { Total }\end{array}$ & 34,93 & 77,21 & 55,88 & 59,31 & 0,0553 & 0,0868 \\
\hline $\begin{array}{l}1 \text { o período } \\
1^{\text {st }} \text { period }\end{array}$ & 36,25 & 85,00 & 117,50 & 133,33 & 0,1490 & 0,5105 \\
\hline $\begin{array}{l}2 \mathrm{o} \text { período } \\
2^{\text {nd }} \text { period }\end{array}$ & 34,56 & 61,03 & 50,73 & 67,65 & 0,5299 & 0,7572 \\
\hline $\begin{array}{l}3 \text { o período } \\
3^{\text {rd }} \text { period }\end{array}$ & 36,54 & 113,46 & $-21,15$ & $-71,79$ & 0,4631 & 0,1661 \\
\hline $\begin{array}{l}\text { Conversão alimentar } \\
\text { Feed efficiency }\end{array}$ & 38,45 & 11,93 & 16,12 & 13,99 & & \\
\hline $\mathrm{L}$ & 0,4599 & 0,2285 & 0,0114 & 0,0003 & & $\operatorname{Pr}>F$ \\
\hline $\mathrm{Q}$ & 0,5473 & 0,4828 & $0,0075^{*}$ & $0,0002 * *$ & & \\
\hline
\end{tabular}

acumulação ocorreria próximo aos seis meses de idade. Resultados semelhantes foram observados por Smith \& White (1997). Corah (1996) verificou absorção de de Mn de 14 a $18 \%$.

Em geral, a exposição crônica a excesso de mineral leva a uma sequiência de eventos bioquímicos antes do aparecimento dos sinais clínicos de disfunção (Underwood \& Suttle, 1999). Primeiro, há aumento do mineral nos locais de armazenamento, com consequiente acúmulo dos metabólitos no sangue, nos tecidos ou na excreta, para, então, os sinais clínicos de disfunção tornarem-se visíveis. Portanto, considerando-se a baixa absorção de $\mathrm{Cd}$ e de $\mathrm{Mn}$, aliada à alta concentração de $\mathrm{Fe} e$ à maior ingestão de milho, é possível que esses fatores, em conjunto, tenham contribuído para maior ganho de peso nos primeiros trinta dias de ingestão de rações com alto percentual de feno de Egeria. Com aumento no tempo de exposição ao mineral, resultante da baixa excreção do $\mathrm{Cd}$, provavelmente a concentração desse elemento nos tecidos tenha atingido nível tóxico, provocando redução e até perda de peso dos animais no último período experimental.

\section{Conclusões}

Apesar da alta concentração de alguns elementos minerais, o feno de Egeria tem potencial como forrageira para ruminantes, desde que fornecido em baixa proporção na ração ou por curto período de tempo.

\section{Literatura Citada}

BINI, M.; THOMAZ, S.M.; MURPHY, K.J. et al. Aquatic macrophyte distribution in relation to water and sediment conditions in the Itaipu Reservoir, Brazil. Hydrobiologia, 415:147-154, 1999.

BROWMER, K.H.; SAINTY, G.R.; SMITH, G. et al. Management of Elodea in Australian irrigation systems. Journal of Aquatic Plant Managment, v.17, p.4-12, 1979.

CHURCH, D.C. The ruminant animal. Digestive physiology and nutrition. Prentice Hall: Englewood Cliffs, 1988. 564p.

CONRAD, J.H.; McDOWELL, L.R.; ELLIS, G.L. et al.Minerais para ruminantes em pastejo em regiões tropicais. Gainesville: Universidade da Florida, 1985. 91p.

CORAH, L. Trace mineral requirement of grazing cattle. Animal Feed Science and Technology, v.59, p.61-70, 1996.

LEE, J.; ROUNCE, J.R.; MACAY, A.D. et al. Accumulation of cadmium with time in Roney sheep grazing ryegrass-white 
clover pasture: effect of cadmium from pasture and soil intake. Australian Journal of Agriculture Research, v.47, p.877-894, 1996.

MARQUES, C.A.T.; BATISTA, A.M.V.; CARVALHO, F.F. R. et al. Composição química e degradabilidade da matéria seca de Egeria densa. In: CONGRESSO DE INICIAÇÃO CIENTÍFICA, 9., 1999, Recife. Anais... Recife: Universidade Federal Rural do Pernambuco, 1999. p.206.

MAURICE, D.V.; JONES, J.E.; DILLON, C.R. et al. Chemical composition and nutritional value of brazilian elodea (Egeria densa) for the chick. Poultry Science, v.63, p.317-323, 1983.

McLAUGHLIN, M.J.; PARKER, D.R.; CLARKE, J.M. Metals and micronutrients - food safety tissues. Field Crops Reserch, v.60, p.143-163, 1999.

NATIONAL RESERCH COUNCIL - NRC. Nutrient requirements of sheep. 6.ed. Washington, D.C.: 1985. 99p.

NATIONAL RESERCH COUNCIL - NRC. Mineral tolerance of domestic animals. Washington, D.C.: 1992. 577p.

NEATHERY, M.W.; MILLER, W.I.; GENTRY, R.P. et al. Cadimium 109 and methyl mercury-203 metabolism tissue distribution and secretion into milk in dairy cows. Journal of Dairy Science, v.57, p.1177-1184, 1974.

ORSKOV, R.E.; Mc DONALD, I. The estimation of protein degradability in the rumen from incubation measurements weighted according to rate of passage. Journal of Agriculture Science, v.92, p.499-503, 1979.

STATISTICAL ANALYSES SYSTEM - SAS. SAS ${ }^{\circledR}$ User's guide: statistics. Version 6. Cary: 1996.

SILVA, D.J. Análise de alimentos (Métodos químicos e biológicos). 2.ed. Viçosa, MG: Universidade Federal de Viçosa, 1990. 165p.
SMITH, G.M.; WHITE, C.L. A molybdenum-sulfur-cadmium interation in sheep. Australian Journal of Agriculture Research, v.48, p.147-154, 1997.

UNDERWOOD, E.J.; SUTTLE, N.F. The mineral nutrition of livestock. 3.ed. New York: CABI Publishing, 1999. 614p.

VALDIVIA, R.; AMMERMAN, C.B.; HENRY, P.R. et al. Effect of dietary aluminium and phosphorus on performance, phosphorus utilization and tissue mineral composition in sheep. Journal of Animal Science, v.55, p.402-410, 1982.

Van BRUWAENE, R.; KIRCHMANN, R.; IMPNS, R. Cadmium contamination in agriculture and zootechnology. Experientia, v.40, p.43-50, 1984.

Van RAVENSWAAY, R.O.; HENRY, P.R.; AMMERMAN, C.B. Effects of time and dietary iron on tissue iron concentration as an estimate of relative bioavailability for ruminants. Animal Feed Science and Technology, v.90, p.185-198, 2001.

WILCOCK, R.J.; CHAMPION, P.D.; NAGELS, J.W. et al. The influence of aquatic macrophytes on the hydraulic and physico-chemical properties of a New Zealand lowland stream. Hydrobiologia, v.416, p.203-214, 1999.

Recebido em: 06/02/02

Aceito em: $01 / 12 / 03$ 